\title{
Estimates of the burden of illness for eight enteric pathogens associated with animal contact in Canada
}

\author{
R. MURRAY, J. TATARYN, K. PINTAR AND M. K. THOMAS* \\ Centre for Foodborne, Environmental and Zoonotic Infectious Diseases, Public Health Agency of Canada, \\ Guelph, Ontario, Canada
}

Received 22 March 2017; Final revision 21 August 2017; Accepted 6 October 2017; first published online 23 November 2017

\section{SUMMARY}

Enteric pathogens are commonly known to be transmitted through food or water; however, contact with animals is another important transmission route. This study estimated the annual burden of illness attributable to animal contact for eight enteric pathogens in Canada. Using data from a Canadian expert elicitation on transmission routes, the proportion of enteric illnesses attributable to animal contact was estimated for each pathogen to estimate the annual number of illnesses, hospitalizations and deaths in Canada. For each estimate, a mean and probability intervals were generated. Of all illnesses caused by these eight pathogens, $16 \%$ were estimated attributable to animal contact. This estimate translates to 86000 (31 000-166 000) illnesses, 488 (186-890) hospitalizations and 12 (2-28) deaths annually for the eight pathogens combined. Campylobacter spp. is the leading cause of illnesses annually, with an estimated 38000 (14000$71000)$ illnesses occurring each year, followed by non-typhoidal Salmonella spp. (17 000, 6000-32 000). The majority of hospitalizations were attributable to non-typhoidal Salmonella spp. (36\%) and Campylobacter spp. (31\%). Non-typhoidal Salmonella spp. (28\%) and Listeria monocytogenes $(31 \%)$ were responsible for the majority of the estimated deaths. These results identify farm animal and pet/pet food exposure as key pathways of transmission for several pathogens. The estimated burden of illness associated with animal contact is substantial.

Key words: Enteric bacteria, epidemiology, water-borne infections.

\section{INTRODUCTION}

Enteric zoonotic pathogens are commonly known to be transmitted through food or water; direct or indirect contact with an animal is another key route of transmission [1-3]. The burden of enteric (acute gastrointestinal) illness associated with contact with farm animals, wildlife, domestic pets and their

\footnotetext{
* Author for correspondence: K. Thomas, Centre for Foodborne, Environmental and Zoonotic Infectious Diseases, Public Health Agency of Canada, 255 Woodlawn Rd W - Unit 120, Guelph, Ontario, Canada N1H 8J1.

(Email: Kate.Thomas@canada.ca)
}

environment is not well known in Canada. Several outbreaks have highlighted pets as an important route of transmission. Salmonellosis outbreaks linked to pet food and treats $[4,5]$, live poultry, reptiles and amphibians, and rodents have been reported in Canada [6-8] and the United States (USA) [9-15] in recent years. Outbreaks of verotoxigenic Escherichia coli (VTEC E. coli) associated with petting zoos have been identified several times [16-19]. In particular children are at a higher risk from this transmission route, given their behaviors (close proximity with pets, petting zoos, more likely to put hands in their mouth, etc.) and developing immune systems [16, 20-23]. 
Case-control studies have identified an increased risk of illness from exposures to animal contact on farms for Campylobacter spp., non-typhoidal Salmonella spp., VTEC O157 [20, 24-26] and specifically contact with cattle for Cryptosporidium infections [27].

Enteric illnesses are underascertained by public health surveillance systems because of underdiagnosis and under-reporting [28]. In order to more accurately estimate the burden of illness associated with animal contact, it is necessary to account for underascertainment and to estimate what proportion of illnesses result from animal transmission, as pathogens rarely are exclusive to one transmission route. To account for the underascertainment at each level of the public health surveillance system (i.e. case seeking medical care, submitting a sample, the sample being tested and found positive, and the positive test result being reported), pathogen-specific multipliers have been used. Estimates related to foodborne illness, and the associated hospitalizations and deaths in Canada and the USA, have been developed using this method of developing underascertainment multipliers and incorporating pathogen-specific source attribution estimates [29, 30].

The USA has estimated the burden of illness (using underascertainment multipliers as described above) associated with animal contact for seven key enteric pathogens and found that $14 \%$ of illnesses are attributed to contact with animals and their environments [31]. Reported case data from the province of Ontario, Canada, identified contact with animals as the primary source of exposure for nearly $20 \%$ of the reported cases due to 14 pathogens [32]. Estimating transmission routes for enteric pathogens is difficult due to the lack of data. Expert elicitations have been conducted in Canada and internationally to estimate the proportion of enteric illnesses attributed to different transmission routes including foodborne and animal contact [33-36].

The objective of this study is to estimate the number of illnesses, hospitalizations and deaths in Canada related to animal contact, using estimates of enteric illness in Canada and the proportion of cases attributed to animal-related contact based on an expert elicitation [37]. The expert elicitation asked 31 Canadian experts to estimate the proportion of cases of 28 pathogens transmitted by five main transmission routes (food, water, animal contact, person-to-person and other) and select subcategories of the food, water and animal contact routes [35, 37]. The current study builds upon the elicitation results by estimating the number of cases related to the animal contact route and subcategories of domestic pets, farm animals and wildlife specifically. These burden estimates can be used to better describe and increase awareness of this public health problem, and inform advocacy, education and further research activities, to prevent and reduce enteric illnesses associated with animal contact.

\section{METHODS}

This study estimated the annual number of animalrelated illnesses, hospitalizations and deaths related to eight key pathogens (Campylobacter spp., non-typhoidal Salmonella spp., Giardia sp., Cryptosporidium spp., VTEC O157, VTEC non-O157, Yersinia enterocolitica and Listeria monocytogenes). Pathogens selection for this study was, in part, based on the seven included in the US study [31] with the addition of Giardia sp., which was selected based on the Canadian expert elicitation attributing $14 \%$ of giardiasis to animal contact. Other zoonotic enteric pathogens were not included due to the lack of available data.

Data focused on the 2000-2010 time period for the underascertainment multipliers and laboratoryconfirmed cases, hospitalizations and deaths and was based on the approximate Canadian 2006 census population (32500 000), to follow the methods published for the burden of foodborne illness in Canada $[28,30]$. Details on specific data sources for the illness estimates and proportion of illness caused by animal contact are provided below. The reported and estimated values used in this analysis are provided as reference in Table 1. All estimates reflect the 2000-2010 time period.

\section{Estimating total illnesses, hospitalizations and deaths}

The methods for estimating the number of domestically acquired foodborne illnesses are described in detail elsewhere [28]. In brief, using this approach of estimating the number of domestically acquired cases by pathogen data on the number of laboratory confirmed cases for seven of the eight pathogens were obtained from national surveillance systems for the time period 2000-2010. These values were then adjusted for under-reporting (i.e. laboratory confirmed but not reported to local/provincial/territorial public health and national surveillance systems) and underdiagnosis (i.e. those who do not seek medical care, sample is not submitted, tested or found positive for causative pathogen) based on data from 


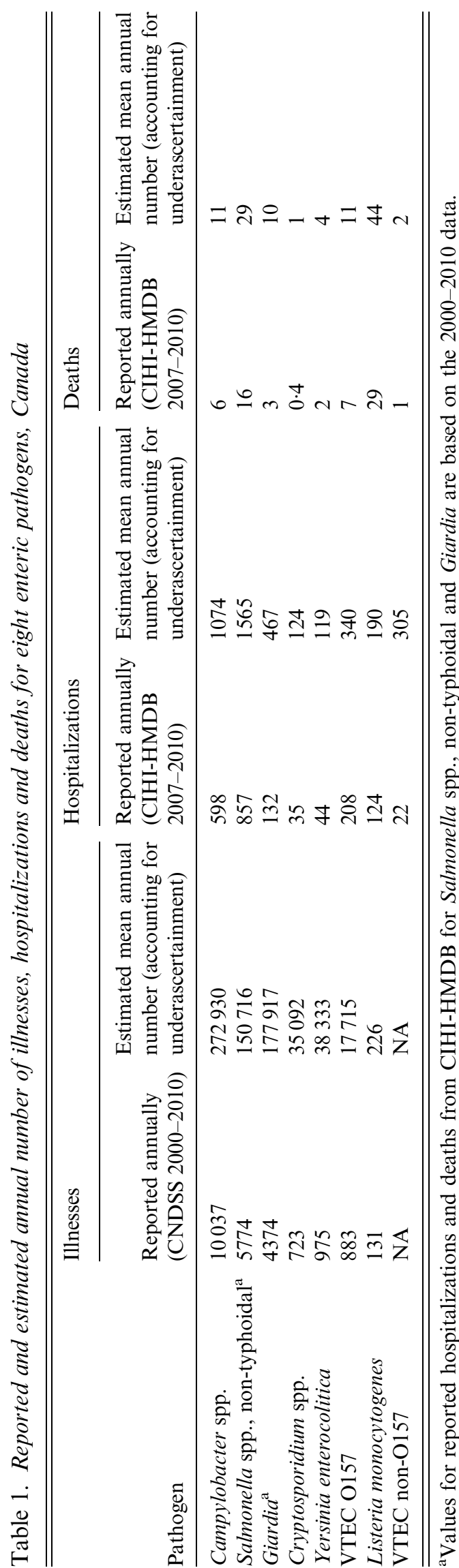

Canadian National Studies on Acute Gastrointestinal Illness (NSAGI) population, laboratory and public health reporting surveys [38-42]. An alternative approach was used for estimating VTEC non-O157 cases, which is not routinely identified and reported in Canada. For VTEC non-O157 cases, a ratio (1 VTEC O157:1.6 VTEC non-O157, based on literature [43]), relative to the estimate of VTEC O157 cases was used $[28,30]$. The methods for estimating the number of domestically acquired foodborne hospitalizations and deaths are described in detail elsewhere [30]. In brief, the methods for estimating hospitalizations and deaths for these eight enteric pathogens relied on the number of hospitalizations and deaths for each pathogen reported in the Canadian Institute for Health Information Hospital Morbidity Database (during the 2000-2010 time period, for certain pathogens only a subset of this time period was available, Table 1) [30,44]. These values were then adjusted for under-reporting (in the hospital database) and underdiagnosis (i.e. sample is not submitted, tested or found positive for causative pathogen). International travel-related illnesses, hospitalizations and deaths were excluded by subtracting the pathogen-specific proportion that is travel-related.

\section{Proportion of illnesses caused by animal contact}

The pathogen-specific proportion of illness attributable to animal contact was estimated using findings from a recently conducted Canadian enteric illness transmission expert elicitation [35]. As reported in the Methods section of the Canadian expert elicitation study, 31 experts estimated the proportion of illnesses caused by 28 pathogens transmitted via major transmission routes (foodborne, waterborne, animal contact, person-to-person and other) and for select subcategories of those major routes, at the point of pathogen consumption. The elicitation consisted of a snowball expert recruitment and collection of background information on experts, an initial online elicitation survey followed by a results discussion and a second online elicitation as an opportunity for experts to modify their initial responses based on the discussion. Animal transmission was defined as an illness transmitted by exposure to animals, i.e. personal contact (hand or mouth) with animal/pet feed, animal/pet fur/coats, saliva or feces (Table 2). The proportion of illnesses from contact with domestic pets, farm animals and wildlife were estimated for non-typhoidal Salmonella spp., Campylobacter spp., Giardia sp., 
Table 2. Definitions of animal contact and subcategory transmission used in expert elicitation survey, Canada 2014 $[35,37]$

\begin{tabular}{ll}
\hline \hline Animal contact & Definitions \\
$\begin{array}{l}\text { Animal contact subcategories } \\
\begin{array}{l}\text { Domestic pets/companion animals } \\
\text { Farm animals }\end{array}\end{array}$ & $\begin{array}{l}\text { Household pets including cats, dogs, rabbits, reptiles and birds } \\
\text { (hand or mouth) with animal/pet feed, animal/pet fur/coats, saliva or feces }\end{array}$ \\
Wildlife & $\begin{array}{l}\text { fairs and animal exhibits } \\
\text { Including dead or live deer, foxes, crows, rats, raccoons, birds }\end{array}$ \\
\hline \hline
\end{tabular}

VTEC O157 and Y. enterocolitica based on the definitions in Table 2 [37]. As previously described, triangular probability distributions were built from the expert estimates for each transmission route and pathogen, using @Risk software (Version 6.1.2; Palisade Corporation, Newfield, NY, USA) from best estimate (most likely) and 5th and 95th percentile values. These were then combined into cumulative distributions, using Monte Carlo simulation with 10000 iterations $[35,37]$.

\section{Analysis}

The median and 90\% credible intervals for the proportion of illnesses due to animal contact and transmission subcategories, by pathogen, as defined by the Canadian expert elicitation, were entered into individual pathogen models as a PERT distribution, where the median and $90 \%$ credible interval values from the expert elicitation were used as the inputs for mean and the upper and lower bounds of the PERT distribution. The @RISK add-in for Microsoft Excel was used, with 100000 iterations to generate a mean and $90 \%$ probability intervals (PIs) for estimates.

\section{RESULTS}

These eight pathogens account for 528279 domestically acquired enteric (acute gastrointestinal) illnesses each year in Canada of which an estimate of 84751 (90\% PI 52 952-123985 were related to animal contact (Table 3)), reflecting approximately $16 \%$ of all domestically acquired enteric illnesses due to these pathogens. An annual incidence rate of 261 illnesses per 100000 Canadians is attributed to animal contact for these eight pathogens. Campylobacter spp. is estimated to cause 38007 (90\% PI 14064-71 600) illnesses each year, the greatest proportion $(45 \%)$ of the total animal-related illnesses estimated. This is followed by 17009 (90\% PI 6137-32 392) non-typhoidal Salmonella spp. (20\%) and 16872 (90\% PI 5886-31 928) Giardia spp. illnesses (20\%).

Illness from these eight pathogens associated with animal contact was estimated to be related to 488 (90\% PI 326-676) hospitalizations and 12 (90\% PI 6-17) deaths (Table 3). Non-typhoidal Salmonella spp. is estimated to cause the most hospitalizations (177; 90\% PI 67-320), followed by Campylobacter spp. (152; 90\% PI 60-268), combining for $67 \%$ of all hospitalizations. Non-typhoidal Salmonella spp. accounted for the greatest number of deaths $(3 ; 90 \%$ PI 0.5-7) along with L. monocytogenes (4; 90\% PI $1-8)$.

Contact with farm animals was the most common cause of animal-associated illnesses, representing almost 42608 (90\% PI $24219-66780)$ illnesses and over half of the illnesses for the five pathogens for which subcategories were estimated (Campylobacter, non-typhoidal Salmonella spp., Giardia sp., VTEC O157 and Y. enterocolitica) (Table 4). An estimated 22333 (90\% PI 7829-43 767) campylobacteriosis illnesses were estimated to be from farm animal contact, Campylobacter spp. also accounted for the highest number of illnesses associated with both domestic pets (10 866, 90\% PI 3301-22 967) and wildlife (6517 illnesses, 90\% PI 1450-15092). Of the $25754(90 \%$ PI 13 955-41 139) annual illnesses associated with domestic pets, for each of the non-typhoidal Salmonella spp. and Giardia sp., about 7000 illnesses were estimated to be related to domestic pets. VTEC O157 and $Y$. enterocolitica illnesses were predominately associated with farm animal contact, with an estimated 1392 (90\% PI 492-2735) and $1926(90 \%$ PI 562-3893) illnesses, respectively, each year. 
Table 3. Estimated number of illnesses attributed to animal contact for eight enteric pathogens, Canada

\begin{tabular}{|c|c|c|c|c|c|c|c|c|c|c|}
\hline Pathogen & $\begin{array}{l}\text { Proportion } \\
\text { attributable to } \\
\text { animal contact } \\
(90 \% \mathrm{CI}) \\
{[35]}\end{array}$ & $\begin{array}{l}\text { Mean number of } \\
\text { illnesses attributable } \\
\text { to animal contact } \\
(\% \text { of total })\end{array}$ & $\begin{array}{l}90 \% \text { PI } \\
\text { (low) }\end{array}$ & $\begin{array}{l}90 \% \text { PI } \\
\text { (high) }\end{array}$ & $\begin{array}{l}\text { Mean number of } \\
\text { hospitalizations } \\
\text { attributable to } \\
\text { animal contact } \\
\text { (\% of total) }\end{array}$ & $\begin{array}{l}90 \% \text { PI } \\
\text { (low) }\end{array}$ & $\begin{array}{l}90 \% \mathrm{PI} \\
\text { (high) }\end{array}$ & $\begin{array}{l}\text { Mean number of } \\
\text { deaths attributable } \\
\text { to animal contact } \\
(\% \text { of total) }\end{array}$ & $\begin{array}{l}90 \% \text { PI } \\
\text { (low) }\end{array}$ & $\begin{array}{l}90 \% \text { PI } \\
\text { (high) }\end{array}$ \\
\hline Campylobacter spp. & $15 \cdot 9(3 \cdot 5-42 \cdot 8)$ & $38007(45)$ & 14064 & 71600 & $152(31)$ & 60 & 268 & $1 \cdot 5(12)$ & $0 \cdot 2$ & 4 \\
\hline Salmonella spp., non-typhoidal & $12 \cdot 7(3 \cdot 0-37 \cdot 9)$ & $17009(20)$ & 6137 & 32392 & $177(36)$ & 67 & 320 & $3(28)$ & $0 \cdot 4$ & 7 \\
\hline Giardia sp. & $13 \cdot 9(2 \cdot 0-35 \cdot 6)$ & $16872(20)$ & 5886 & 31928 & $44(9)$ & 15 & 84 & $1(8)$ & $0 \cdot 0$ & 3 \\
\hline Cryptosporidium spp. & $23(4 \cdot 9-57 \cdot 1)$ & $6305(7)$ & 2201 & 12861 & $22(5)$ & 7 & 47 & $0 \cdot 2(2)$ & $0 \cdot 0$ & 1 \\
\hline VTEC non-O157 & $12 \cdot 3(2 \cdot 5-33 \cdot 4)$ & $4017(5)$ & 1130 & 8722 & $37(8)$ & 13 & 70 & $1(8)$ & $0 \cdot 2$ & 3 \\
\hline Yersinia enterocolitica & $6 \cdot 7(0 \cdot 06-19 \cdot 3)$ & $2522(3)$ & 592 & 3291 & $8(2)$ & 2 & 15 & $1(9)$ & $0 \cdot 4$ & 2 \\
\hline VTEC O157 & $9 \cdot 6(3 \cdot 6-17 \cdot 5)$ & $1678(2)$ & 738 & 5083 & $32(7)$ & 17 & 52 & $0 \cdot 3(2)$ & $0 \cdot 0$ & 1 \\
\hline Listeria monocytogenes & $6 \cdot 5(0 \cdot 05-26 \cdot 1)$ & $19(0)$ & 4 & 39 & $16(3)$ & 4 & 33 & $4(31)$ & 1 & 8 \\
\hline Total & & 84751 & 52952 & 123985 & 488 & 326 & 676 & 12 & 6 & 17 \\
\hline
\end{tabular}

Table 4. Estimated number of illnesses attributed to subcategory routes of animal contact for five enteric pathogens, Canada

\begin{tabular}{|c|c|c|c|c|c|c|c|c|c|c|c|c|}
\hline \multirow[b]{2}{*}{ Pathogen } & \multicolumn{4}{|c|}{ Domestic pets/companion animal contact } & \multicolumn{4}{|c|}{ Farm animal contact } & \multicolumn{4}{|l|}{ Wildlife contact } \\
\hline & $\begin{array}{l}\text { Proportion } \\
\text { attributable } \\
(90 \% \mathrm{CI}) \\
{[37]}\end{array}$ & $\begin{array}{l}\text { Mean number } \\
\text { of illnesses } \\
\text { attributable } \\
(\% \text { of total) }\end{array}$ & $\begin{array}{l}90 \% \text { PI } \\
\text { (low) }\end{array}$ & $\begin{array}{l}90 \% \text { PI } \\
\text { (high) }\end{array}$ & $\begin{array}{l}\text { Proportion } \\
\text { attributable } \\
(90 \% \mathrm{CI}) \\
{[37]}\end{array}$ & $\begin{array}{l}\text { Mean number } \\
\text { of illnesses } \\
\text { attributable } \\
\text { (\% of total) }\end{array}$ & $\begin{array}{l}90 \% \text { PI } \\
\text { (low) }\end{array}$ & $\begin{array}{l}90 \% \mathrm{Pl} \\
\text { (high) }\end{array}$ & $\begin{array}{l}\text { Proportion } \\
\text { attributable } \\
(90 \% \mathrm{CI}) \\
{[37]}\end{array}$ & $\begin{array}{l}\text { Mean number } \\
\text { of illnesses } \\
\text { attributable } \\
\text { (\% of total) }\end{array}$ & $\begin{array}{l}90 \% \mathrm{Pl} \\
\text { (low) }\end{array}$ & $\begin{array}{l}90 \% \mathrm{Pl} \\
\text { (high) }\end{array}$ \\
\hline Campylobacter spp. & $27 \cdot 5(8 \cdot 0-53 \cdot 6)$ & $10866(42)$ & 3301 & 22967 & $57 \cdot 6(35 \cdot 1-87 \cdot 0)$ & $22333(52)$ & 7829 & 43767 & $14 \cdot 9(1 \cdot 2-41 \cdot 2)$ & $6517(63)$ & 1450 & 15092 \\
\hline $\begin{array}{l}\text { Salmonella spp., } \\
\text { non-typhoidal }\end{array}$ & $39 \cdot 8(11 \cdot 8-75 \cdot 9)$ & $7001(27)$ & 2099 & 14864 & $52 \cdot 6(21 \cdot 3-87 \cdot 6)$ & $9049(21)$ & 2914 & 18497 & $7 \cdot 6(1 \cdot 9-13 \cdot 3)$ & $1293(13)$ & 388 & 2721 \\
\hline Giardia sp. & $42 \cdot 5(17-66 \cdot 8)$ & $7136(28)$ & 2261 & 14465 & $48(15 \cdot 8-73 \cdot 4)$ & 7908 (19) & 2480 & 16096 & $9 \cdot 5(0 \cdot 8-30 \cdot 9)$ & $2163(21)$ & 675 & 4508 \\
\hline $\begin{array}{l}\text { Yersinia } \\
\text { enterocolitica }\end{array}$ & $5 \cdot 3(3 \cdot 4-7 \cdot 3)$ & $662(3)$ & 128 & 1599 & $83(76 \cdot 8-89 \cdot 1)$ & $1926(5)$ & 562 & 3893 & $11 \cdot 7(6 \cdot 5-16 \cdot 9)$ & $117(1)$ & 23 & 280 \\
\hline VTEC O157 & $23 \cdot 3(1 \cdot 8-62 \cdot 6)$ & $89(0)$ & 30 & 179 & $72 \cdot 5(31 \cdot 7-95 \cdot 8)$ & $1392(3)$ & 492 & 2735 & $4 \cdot 2(0 \cdot 4-10 \cdot 7)$ & $196(2)$ & 65 & 399 \\
\hline Total & & 25754 & 13955 & 41139 & & 42608 & 24219 & 66780 & & 10286 & 4569 & 19170 \\
\hline
\end{tabular}




\section{DISCUSSION}

These are the first Canadian estimates of illness attributed to animal contact, accounting for under-reporting and underdiagnosis of illnesses. This study contributes to the development of an understanding of the overall burden of enteric illness in Canada. To date, estimates of foodborne illness [28] and acute gastrointestinal illness associated with drinking water $[45,46]$ have been completed. This is the first study to estimate illness specifically associated with subcategories of animal contact for farm animals, pets and wildlife. These estimates provide a relative comparison of transmission pathways and dominant sources of enteric illness, which is critical when identifying public health priorities, designing effective interventions, and providing evidence to inform policy and regulatory decisionmaking at the local, provincial and federal level in Canada. In addition, burden studies help to identify priority pathogens of concern domestically, and knowledge gaps for further research.

Comparing the same seven pathogens included in the US study [31], more illnesses were associated with animal contact in Canada than in the USA, estimating 209 cases per 100000 Canadians $v s$. an estimated 149 cases per 100000 in the USA [47]. This is likely due to the differences in total illness estimates as well as generally lower proportions of illness estimated to be via animal transmission in the USA, which relied primarily on case-control studies and outbreak summaries to inform the US inputs. The values used for the proportion of illness attributed to animal contact in Canada from the expert elicitation are within the range of values reported in international studies from the USA, Australia and the Netherlands [31, 33, 34, 36] as well as Canadian studies, using surveillance data and reported exposures [32, 48, 49] (Table 5).

This study highlights farm and animal/pet food exposure as an important pathway for illness transmission. Illness associated with farm animals may occur from occupational exposures, such as Campylobacter spp. infection among workers at poultry-processing plants [50, 51], non-typhoidal Salmonella spp. infection following contact with baby chicks [52] or visiting a petting zoo [2]. Reptiles and related feeder rodents may be responsible for a substantial portion of the petrelated Salmonella spp. illnesses estimated [1, 7, 22, 53]. It was estimated in the USA that $6 \%$ of all sporadic Salmonella infections may be attributable to reptiles or amphibians [54]. While younger puppies may contribute to Campylobacter infections [55], pet food has also been found to be a concern for exposure to enteric pathogens [56, 57].

Canadians' exposure to various animals and pathogen prevalence is an important context to understanding public health risk related to the animal contact transmission route. A Canadian 2015 population study, estimated in the past 7 days that $63.4 \%$ of Canadians have 'any contact with animals, animal waste, habitat or food', $6.9 \%$ visit a farm or barn, and $1 \cdot 1 \%$ and $1.3 \%$ visit any petting zoo or an agricultural fair, respectively [58]. The likelihood of enteric pathogen transmission from household pets may be lower compared with an encounter with farm animals; the higher frequency of pet contact [59] would suggest this as an important potential route of transmission.

The prevalence of Campylobacter spp. has been reported to be approximately $6.5 \%$ for petting zoo animals and $24 \cdot 7 \%$ for household pets [60]. Both of these animal sources have a generally lower prevalence compared with FoodNet Canada data from farms for swine $(85 \%)$, beef cattle $(78 \%)$ and dairy cattle $(79 \%)$ [61]. The prevalence of non-typhoidal Salmonella spp. detected in animals on farms (swine, broiler chickens, beef and dairy cattle) by the FoodNet Canada surveillance in sentinel sites across Canada was generally lower than Campylobacter spp. [61].

Less is understood about wildlife-associated transmission; based on our study findings, the burden associated with wildlife for all pathogens is notable and the estimated illness associated with Campylobacter spp. and non-typhoidal Salmonella spp. is considerable. Wild birds may be a primary source of these estimated illnesses as identified as a source of transmission in the United Kingdom (UK) and France [62-64]. It is estimated in the UK that about 10000 illnesses may be associated with wild birds each year [62]. Garden birds, playgrounds and beach sand activities may be environments where wild birds and human behavior intersect causing illness [65, 66]. Rural wildlife exposure through hunting is also a potential route of transmission and there is evidence that exposure to deer and wild boars may be a source for shiga toxin-producing E. coli and Y. enterocolitica [67-69].

Limitations of these enteric illness estimate models and the expert elicitation study have been discussed elsewhere [28, 30, 35, 37]. General limitations concerning uncertainty of illness estimate models and potential bias of expert elicitations apply (recruitment, elicitation tool, question framing, methodology and analysis) and have also been discussed elsewhere [70-72]. These estimates reflect illnesses for the time 
Table 5. Comparison of the estimated proportion of domestic cases (and credible intervals (CI)) for eight enteric pathogens attributed to animal contact in previously published Canadian and International studies

\begin{tabular}{|c|c|c|c|c|c|c|c|c|}
\hline \multirow[b]{2}{*}{ Pathogen } & \multicolumn{4}{|l|}{ Expert elicitation } & \multirow{2}{*}{$\begin{array}{l}\text { Other }^{\mathrm{a}} \\
\text { USA [31] } \\
\% \text { (range) }\end{array}$} & \multicolumn{3}{|c|}{ Canadian epidemiological studies on reported cases } \\
\hline & $\begin{array}{l}\text { Canada [35] } \\
\text { Median }(90 \% \text { CI) }\end{array}$ & $\begin{array}{l}\text { Australia [33] } \\
\text { Median }(95 \% \text { CI) }\end{array}$ & $\begin{array}{l}\text { The Netherlands [34] } \\
\text { Mean }(95 \% \mathrm{CI})\end{array}$ & $\begin{array}{l}\text { WHO/FERG- } \\
\text { subregion A [36] } \\
\text { Median (95\% CI) }\end{array}$ & & $\begin{array}{l}\text { Ontario, } \\
\text { Canada [32] } \\
\text { Mean }\end{array}$ & $\begin{array}{l}\text { Canada FoodNet } \\
\text { Site [49] } \\
\text { Mean }\end{array}$ & $\begin{array}{l}\text { Canada FoodNet } \\
\text { Site }[48] \\
\text { Mean }\end{array}$ \\
\hline Campylobacter spp. & $15 \cdot 9(3 \cdot 5-42 \cdot 8)$ & $10(2-10)$ & $19(0-60)$ & $11(0-37)$ & $17(9-29)$ & $26 \cdot 9$ & $16 \cdot 7$ & 20 \\
\hline $\begin{array}{l}\text { Salmonella spp., } \\
\text { non-typhoidal }\end{array}$ & $12 \cdot 7(3-37 \cdot 9)$ & $4(1-9)$ & $9(0-19)$ & $10(0-39)$ & $11(6-20)$ & $15 \cdot 2$ & $10 \cdot 7$ & $21 \cdot 3$ \\
\hline Giardia sp. & $13 \cdot 9(2 \cdot 1-35 \cdot 6)$ & - & $11(0-20)$ & $14(0-41)$ & - & $14 \cdot 2$ & $9 \cdot 8^{\mathrm{b}}$ & - \\
\hline Cryptosporidium spp. & $23 \cdot 0(4 \cdot 9-57 \cdot 1)$ & - & $13(5-19)$ & $10(1-42)$ & $16(9-28)$ & $47 \cdot 2$ & $9 \cdot 8^{\mathrm{b}}$ & - \\
\hline VTEC non-O157 & $12 \cdot 3(2 \cdot 5-33 \cdot 4)$ & - & - & - & $8(4-15)$ & - & - & - \\
\hline Yersinia enterocolitica & $6 \cdot 7(0 \cdot 6-17 \cdot 5)$ & - & - & - & $1(0 \cdot 5-2)$ & $15 \cdot 5$ & - & - \\
\hline VTEC O157 & $9 \cdot 6(3 \cdot 6-17 \cdot 5)$ & $17(2-35)$ & $21(0-76)$ & $13(0-41)$ & $6(3-11)$ & $18 \cdot 4^{\mathrm{c}}$ & 19 & $9 \cdot 4$ \\
\hline Listeria monocytogenes & $6 \cdot 5(0 \cdot 5-29 \cdot 6)$ & $1(0-3)$ & $5(0-13)$ & - & $1(0 \cdot 5-2)$ & $8 \cdot 3$ & - & - \\
\hline
\end{tabular}

${ }^{a}$ Data sources identified in the USA include Foodnet case-control studies for Campylobacter spp., STEC O157, Listeria monocytogenes, Salmonella spp., non-typhoidal and Cryptosporidium spp. Additionally outbreaks were used for STEC O157, STEC non-O157 and Salmonella spp., non-typhoidal. There were limited data for Yersinia enterocolitica.

${ }^{\mathrm{b}}$ Giardia sp. and Cryptosporidium spp. combined.

${ }^{\mathrm{c}}$ All VTEC combined. 
period of 2000-2010 and recent changes in rates of illness for pathogens, such as the reported decrease in $E$. coli $\mathrm{O} 157$ cases in Canada in recent years [73] are not reflected in these results and should be considered when interpreting. Sources of information related to the attribution of illness to the animal/pet contact transmission route are limited.

Selection of pathogens to be included may have some limitations as transmission of VTEC non-O157, $Y$. enterocolitica, L. monocytogenes and Giardia sp. via animal contact is less well known. Contact with farm and domestic animals has been identified as a risk factor for VTEC non-O157 [74, 75] and $Y$. enterocolitica, respectively [76]. While the evidence is less clear for L. monocytogenes, transmission from animal to human is plausible, as Listeria has been identified in pet food [77], urban poultry flocks [78] and at least one study identified living on a cattle farm as an increased risk of listeriosis [79]. Other countries have also estimated that a small proportion of listeriosis cases may be transmitted via animal contact [31, 33, 34] (Table 5). Animal contact transmission of Giardia sp. may be relatively uncommon as current molecular epidemiological data suggests that animals are more often infected with species-specific assemblages that do not cause disease in humans [60, 80-82]. Molecular characterization of Giardia sp. in patients in Northern Canada found suggestive zoonotic transmission [83]. Furthermore, animal contact has been implicated in three reported giardiasis outbreaks in a review of Giardia sp. outbreaks in the USA (1971-2011), associated with rabbits at a petting zoo, cattle at a farm and a pet reptile at a long-term care facility [84].

The approach used in this study, which is similar to the US approach [31], assumes that the disease severity and frequency with which cases are underdiagnosed are independent of the mode of transmission. In addition, we estimated the overall pathogen-specific proportion of illnesses attributable to animal contact; the proportion of illnesses attributable to animal contact may vary by age because of the differences in exposures and behaviors [31]. The hospitalizations and death estimates may therefore be conservative, as they do not reflect a potential increased representation of illness in children due to this transmission route. The role of sick $v s$. healthy animals and immunity are not explored in these estimates but are worth considering in future studies when more data become available to differentiate risks at the individual level.

To further understand transmission dynamics and the burden of illness to specific animals, case-control studies for key pathogens to identify specific higher risk animals/settings and risk behaviors facilitating transmission would be beneficial. Additionally, assessment of exposure frequency among Canadians, studies to collect data on pathogen prevalence, concentration and subtyping in relevant animal populations and mechanisms for pathogen reduction for some pets (e.g. reptiles) would further support the understanding of the role animal contact plays in enteric illness transmission and burden.

The burden of enteric infection associated with animal contact is considerable and emphasizes the need for prevention activities. Enhanced awareness and education for the public, farm/occupational workers and pet owners about the potential risk of illness associated with animal contact is key to preventing animal contact-associated illnesses. This includes highlighting the importance of preventative behaviors through consistent messaging at veterinarian offices, pet stores, petting zoos and other venues and reinforcing their role in preventing illness (e.g. recommendations identified in Reducing the Risk of Pet-Associated Zoonotic Infections [3]) and broader communication through websites promoting safe pet ownership, such as the Worms and Germs Blog (http://www.wormsandgermsblog.com) [85] and Healthy Animals, Healthy People [86]. Public health guidance (e.g. petting zoo infection prevention guidelines, recommendations for high-risk populations) and implementation of public health interventions (e.g. enhanced awareness, hand-washing stations) will also contribute to reducing the burden of enteric illness associated with animals. The evaluation of best practices and identification of the most effective prevention activities to reduce disease are required [3].

\section{ACKNOWLEDGEMENTS}

The authors would like to thank our colleagues (from federal and provincial governments and academic institutions) who provided consultation on this study.

\section{DECLARATION OF INTEREST}

All authors declare no competing interests, nor financial gain, related to this work.

\section{REFERENCES}

1. Hoelzer K, Moreno Switt AI, Wiedmann M. Animal contact as a source of human non-typhoidal salmonellosis. Veterinary Research 2011; 42: 34.

2. Steinmuller N, et al. Outbreaks of enteric disease associated with animal contact: not just a foodborne 
problem anymore. Clinical Infectious Diseases 2006; 43: 1596-1602.

3. Stull JW, Brophy J, Weese JS. Reducing the risk of pet-associated zoonotic infections. Canadian Medical Association Journal 2015; 187: 736-743.

4. Centers for Disease Control and Prevention (CDC). Multistate outbreak of human Salmonella typhimurium infections associated with pet turtle exposure - United States, 2008. MMWR. Morbidity and Mortality Weekly Report 2010; 59: 191-196.

5. Centers for Disease Control and Prevention (CDC). Multistate outbreak of human Salmonella typhimurium infections associated with aquatic frogs - United States, 2009. MMWR. Morbidity and Mortality Weekly Report 2010; 58: 1433-1436.

6. Public Health Notice. Outbreak of Salmonella infections related to contact with live baby poultry (http://www. phac-aspc.gc.ca/phn-asp/2015/salmonella-eng.php). Accessed 22 March 2016.

7. Public Health Notice. Outbreak of Salmonella infections related to contact with snakes and rodents used to feed them (http://www.phac-aspc.gc.ca/phn-asp/2014/salmonella-sr-eng.php). Accessed 22 March 2016.

8. Brisdon S, Galanis E, Colindres R. An international outbreak of human salmonellosis associated with animalderived pet treats - Canada and Washington state, 2005. Canada Communicable Disease Report 2006; 32: 150-155.

9. Cartwright EJ, et al. A multistate investigation of antibiotic-resistant Salmonella enterica serotype I 4, [5],12:i:- infections as part of an international outbreak associated with frozen feeder rodents. Zoonoses and Public Health 2016; 63: 62-71.

10. Nakao JH, et al. 'One health' investigation: outbreak of human Salmonella braenderup infections traced to a mail-order hatchery - United States, 2012-2013. Epidemiology and Infection 2015; 143: 2178-2186.

11. Behravesh CB, et al. Human Salmonella infections linked to contaminated dry dog and cat food, 20062008. Pediatrics 2010; 126: 477-483.

12. Lowther SA, et al. Foodborne outbreak of Salmonella subspecies IV infections associated with contamination from bearded dragons. Zoonoses and Public Health 2011; 58: 560-566.

13. Clark C, et al. Characterization of Salmonella associated with pig ear dog treats in Canada. Journal of Clinical Microbiology 2001; 39: 3962-3968.

14. Centers for Disease Control and Prevention (CDC). Notes from the field: multistate outbreak of human Salmonella typhimurium infections linked to contact with pet hedgehogs - United States, 2011-2013. MMWR. Morbidity and Mortality Weekly Report 2013; 62: 73.

15. Imanishi M, et al. Outbreak of Salmonella enterica serotype Infantis infection in humans linked to dry dog food in the United States and Canada, 2012. Journal of the American Veterinary Medical Association 2014; 244: 545-553.

16. David ST, et al. Petting zoo-associated Escherichia coli 0157:h7 - secondary transmission, asymptomatic infection, and prolonged shedding in the classroom. Canada Communicable Disease Report 2004; 30: 173-180.
17. Warshawsky B, et al. Outbreak of Escherichia coli $0157: \mathrm{H} 7$ related to animal contact at a petting zoo. The Canadian Journal of Infectious Diseases 2002; 13: 175-181.

18. Centers for Disease Control and Prevention (CDC). Outbreaks of Escherichia coli $\mathrm{O} 157: \mathrm{H} 7$ associated with petting zoos - North Carolina, Florida, and Arizona, 2004 and 2005. MMWR. Morbidity and Mortality Weekly Report 2005; 54: 1277-1280.

19. Goode B, et al. Outbreak of Escherichia coli O157: H7 infections after petting zoo visits, North Carolina State Fair, October-November 2004. Archives of Pediatrics \& Adolescent Medicine 2009; 163: 42-48.

20. Friedman CR, et al. Risk factors for sporadic Campylobacter infection in the United States: a casecontrol study in FoodNet sites. Clinical Infectious Diseases 2004; 38(Suppl 3): S285-S296.

21. Meyer Sauteur PM, et al. Risk factors for invasive reptile-associated salmonellosis in children. Vector Borne and Zoonotic Diseases (Larchmont, N.Y.) 2013; 13: 419-421.

22. Murphy D, Oshin F. Reptile-associated salmonellosis in children aged under 5 years in South West England. Archives of Disease in Childhood 2015; 100: 364-365.

23. Jones TF, et al. A case-control study of the epidemiology of sporadic Salmonella infection in infants. Pediatrics 2006; 118: 2380-2387.

24. Cole D, et al. Attributing sporadic and outbreakassociated infections to sources: blending epidemiological data. Epidemiology and Infection 2014; 142: 295-302.

25. Domingues AR, et al. Source attribution of human campylobacteriosis using a meta-analysis of case-control studies of sporadic infections. Epidemiology and Infection 2012; 140: 970-981.

26. Domingues AR, et al. Source attribution of human salmonellosis using a meta-analysis of case-control studies of sporadic infections. Epidemiology and Infection 2012; 140: 959-969.

27. Roy SL, et al. Risk factors for sporadic cryptosporidiosis among immunocompetent persons in the United States from 1999 to 2001. Journal of Clinical Microbiology 2004; 42: 2944-2951.

28. Thomas MK, et al. Estimates of the burden of foodborne illness in Canada for 30 specified pathogens and unspecified agents, circa 2006. Foodborne Pathogens and Disease 2013; 10: 639-648.

29. Scallan E, et al. Foodborne illness acquired in the United States - major pathogens. Emerging Infectious Diseases 2011; 17: 7-15.

30. Thomas MK, et al. Estimates of foodborne illnessrelated hospitalizations and deaths in Canada for 30 specified pathogens and unspecified agents. Foodborne Pathogens and Disease 2015; 12: 820-827.

31. Hale CR, et al. Estimates of enteric illness attributable to contact with animals and their environments in the United States. Clinical Infectious Diseases 2012; 54(Suppl 5): S472-S479.

32. Vrbova L, et al. A descriptive study of reportable gastrointestinal illnesses in Ontario, Canada, from 2007 to 2009. BMC Public Health 2012; 12: 970. 
33. Vally H, et al. Proportion of illness acquired by foodborne transmission for nine enteric pathogens in Australia: an expert elicitation. Foodborne Pathogens and Disease 2014; 11: 727-733.

34. Havelaar AH, et al. Attribution of foodborne pathogens using structured expert elicitation. Foodborne Pathogens and Disease 2008; 5: 649-659.

35. Butler AJ, Thomas MK, Pintar KD. Expert elicitation as a means to attribute 28 enteric pathogens to foodborne, waterborne, animal contact, and person-to-person transmission routes in Canada. Foodborne Pathogens and Disease 2015; 12: 335-344.

36. Hald T, et al. World Health Organization estimates of the relative contributions of food to the burden of disease due to selected foodborne hazards: a structured expert elicitation. PLoS ONE 2016; 11: e0145839.

37. Butler AJ, Pintar KD, Thomas MK. Estimating the relative role of various subcategories of food, water, and animal contact transmission of 28 enteric diseases in Canada. Foodborne Pathogens and Disease 2016; 13: 57-64.

38. Flint JA, et al. From stool to statistics: reporting of acute gastrointestinal illnesses in Canada. Canadian Journal of Public Health 2004; 95: 309-313.

39. Flint J. Report of the 2001 Canadian Laboratory Study-National Studies on Acute Gastrointestinal Illness. Guelph: Government of Canada, 2002.

40. Majowicz SE, et al. Magnitude and distribution of acute, self-reported gastrointestinal illness in a Canadian community. Epidemiology and Infection 2004; 132: 607-617.

41. Thomas MK, et al. Population distribution and burden of acute gastrointestinal illness in British Columbia, Canada. BMC Public Health 2006; 6: 307.

42. Sargeant JM, Majowicz SE, Snelgrove J. The burden of acute gastrointestinal illness in Ontario, Canada, 20052006. Epidemiology and Infection 2008; 136: 451-460.

43. Chui L, et al. Prevalence of shiga toxin-producing Escherichia coli as detected by enzyme-linked immunoassays and real-time PCR during the summer months in northern Alberta, Canada. Journal of Clinical Microbiology 2011; 49: 4307-4310.

44. Canadian Institute for Health Information. Hospital Morbidity Database. Ottawa, Canada: Canadian Institute for Health Information, 2000-2010.

45. Murphy HM, et al. Estimating the number of cases of acute gastrointestinal illness (AGI) associated with Canadian municipal drinking water systems. Epidemiology and Infection 2016; 144: 1371-1385.

46. Murphy HM, et al. Estimating the burden of acute gastrointestinal illness due to Giardia, Cryptosporidium, Campylobacter, E. coli $\mathrm{O} 157$ and norovirus associated with private wells and small water systems in Canada. Epidemiology and Infection 2016; 144: 1355-1370.

47. Uehlinger FD, et al. Zoonotic potential of Giardia duodenalis and Cryptosporidium spp. and prevalence of intestinal parasites in young dogs from different populations on Prince Edward Island, Canada. Veterinary Parasitology 2013; 196: 509-514.
48. Dumoulin D, et al. Informing source attribution of enteric disease: an analysis of public health inspectors' opinions on the 'most likely source of infection'. Environmental Health Review 2012; 55: 27-36.

49. Lukacsovics A, et al. Using environmental health officers' opinions to inform the source attribution of enteric disease: further analysis of the 'most likely source of infection'. BMC Public Health 2014; 14: 1258.

50. Ellstrom P, et al. A prospective follow-up study on transmission of Campylobacter from poultry to abattoir workers. Foodborne Pathogens and Disease 2014; 11: 684-688.

51. de Perio MA, et al. Campylobacter infection in poultryprocessing workers, Virginia, USA, 2008-2011. Emerging Infectious Diseases 2013; 19: 286-288.

52. Behravesh CB, et al. Backyard poultry flocks and salmonellosis: a recurring, yet preventable public health challenge. Clinical Infectious Diseases 2014; 58: 1432-1438.

53. Damborg P, et al. Bacterial zoonoses transmitted by household pets: state-of-the-art and future perspectives for targeted research and policy actions. Journal of Comparative Pathology 2016; 155(Suppl. 1): S27-S40.

54. Mermin J, et al. Reptiles, amphibians, and human Salmonella infection: a population-based, case-control study. Clinical Infectious Diseases 2004;38(Suppl 3): S253-S261.

55. Stafford RJ, et al. Population-attributable risk estimates for risk factors associated with Campylobacter infection, Australia. Emerging Infectious Diseases 2008; 14: 895-901.

56. Lambertini E, et al. Quantitative assessment of human and pet exposure to Salmonella associated with dry pet foods. International Journal of Food Microbiology 2016; 216: 79-90.

57. Lambertini E, et al. Transmission of bacterial zoonotic pathogens between pets and humans: the role of pet food. Critical Reviews in Food Science and Nutrition 2015; 17: 364-418.

58. Public Health Agency of Canada. Foodbook Report. Ottawa: Public Health Agency of Canada, 2015 (https://www.canada.ca/en/public-health/services/publications/food-nutrition/foodbook-report.html).

59. David JM, et al. Assessing multiple foodborne, waterborne and environmental exposures of healthy people to potential enteric pathogen sources: effect of age, gender, season, and recall period. Epidemiology and Infection 2014; 142: 28-39.

60. Pintar KD, et al. A systematic review and meta-analysis of the Campylobacter spp. prevalence and concentration in household pets and petting zoo animals for use in exposure assessments. PLoS ONE 2015; 10: e0144976.

61. Public Health Agency of Canada. FoodNet Canada Short Report 2014. Guelph: Public Health Agency of Canada, 2015.

62. Cody AJ, et al. Wild bird associated Campylobacter jejuni isolates are a consistent source of human disease, in Oxfordshire, United Kingdom. Environmental Microbiology Reports 2015; 7: 782-788. 
63. French NP, et al. Molecular epidemiology of Campylobacter jejuni isolates from wild-bird fecal material in children's playgrounds. Applied and Environmental Microbiology 2009; 75: 779-783.

64. Lawson B, et al. Epidemiological evidence that garden birds are a source of human salmonellosis in England and Wales. PLOS ONE 2014; 9: e88968.

65. Heaney CD, et al. Fecal indicators in sand, sand contact, and risk of enteric illness among beachgoers. Epidemiology (Cambridge, Mass.) 2012; 23: 95-106.

66. Heaney CD, et al. Contact with beach sand among beachgoers and risk of illness. American Journal of Epidemiology 2009; 170: 164-172.

67. Miko A, et al. Assessment of Shiga toxin-producing Escherichia coli isolates from wildlife meat as potential pathogens for humans. Applied and Environmental Microbiology 2009; 75: 6462-6470.

68. Sanno A, et al. Presence of Salmonella spp., Yersinia enterocolitica, Yersinia pseudotuberculosis and Escherichia coli $\mathrm{O} 157: \mathrm{H} 7$ in wild boars. Epidemiology and Infection 2014; 142: 2542-2547.

69. Wacheck $\mathbf{S}$, et al. Wild boars as an important reservoir for foodborne pathogens. Foodborne Pathogens and Disease 2010; 7: 307-312.

70. Butler AJ, Thomas MK, Pintar KD. Systematic review of expert elicitation methods as a tool for source attribution of enteric illness. Foodborne Pathogens and Disease 2015; 12: 367-382.

71. Glass K, Ford L, Kirk MD. Drivers of uncertainty in estimates of foodborne gastroenteritis incidence. Foodborne Pathogens and Disease 2014; 11: 938-944.

72. Vally H, et al. Evaluation of a structured expert elicitation estimating the proportion of illness acquired by foodborne transmission for nine enteric pathogens in Australia. Epidemiology and Infection 2016; 144: 897-906.

73. Public Health Agency of Canada. National Enteric Surveillance Program 2013 Annual Report. Guelph: Public Health Agency of Canada, 2015.

74. Byrne L, et al. Epidemiology and microbiology of Shiga toxin-producing Escherichia coli other than serogroup O157 in England, 2009-2013. Journal of Medical Microbiology 2014; 63: 1181-1188.
75. Friesema IH, et al. Risk factors for sporadic Shiga toxin-producing Escherichia coli $\mathrm{O} 157$ and nonO157 illness in The Netherlands, 2008-2012, using periodically surveyed controls. Epidemiology and Infection 2015; 143: 1360-1367.

76. Boqvist S, et al. Sources of sporadic Yersinia enterocolitica infection in children in Sweden, 2004: a case-control study. Epidemiology and Infection 2009; 137: 897-905.

77. Nemser SM, et al. Investigation of Listeria, Salmonella, and toxigenic Escherichia coli in various pet foods. Foodborne Pathogens and Disease 2014; 11: 706-709.

78. Crespo R, et al. Outbreak of Listeria monocytogenes in an urban poultry flock. BMC Veterinary Research 2013; 9: 204.

79. Varma JK, et al. Listeria monocytogenes infection from foods prepared in a commercial establishment: a casecontrol study of potential sources of sporadic illness in the United States. Clinical Infectious Diseases 2007; 44: 521-528.

80. Hunter PR, Thompson RC. The zoonotic transmission of Giardia and Cryptosporidium. International Journal for Parasitology 2005; 35: 1181-1190.

81. Xiao L, Fayer R. Molecular characterisation of species and genotypes of Cryptosporidium and Giardia and assessment of zoonotic transmission. International Journal for Parasitology 2008; 38: 1239-1255.

82. Ryan U, Caccio SM. Zoonotic potential of Giardia. International Journal for Parasitology 2013; 43: 943-956.

83. Iqbal A, et al. Prevalence and molecular characterization of Cryptosporidium spp. and Giardia duodenalis in diarrhoeic patients in the Qikiqtani Region, Nunavut, Canada. International Journal of Circumpolar Health 2015; 74: 27713.

84. Adam EA, et al. Giardiasis outbreaks in the United States, 1971-2011. Epidemiology and Infection 2016; 144: $2790-2801$.

85. Worms and Germs Blog (http://www.wormsandgermsblog.com). Accessed 22 March 2016.

86. Healthy Animals, Healthy People (http://healthycanadians.gc.ca/publications/healthy-living-vie-saine/ poster-healthy-animals-affiche-animaux-en-sante/indexeng.php). Accessed 24 April 2016. 